American Journal of Applied Sciences 6 (4): 788-796, 2009

ISSN 1546-9239

(C) 2009 Science Publications

\title{
The Effect of the Harmonics, the Fault Location and the Fault Resistance on the Performance of the Impedance-Type Distance Relay
}

\author{
A.S. Khraiwish, M. Alshamasin, R. Kassasbeh, Y. Al shiboul, Z. Al-Qudah and M. Al-Busoul \\ Faculty of Engineering Technology, Al-Balqa'a Applied University, Amman, Jordan
}

\begin{abstract}
One of today's trends is continuously increasing the number and the power ratings of the non-linear loads connected to the electric power systems. These non-linear loads, such as powerelectronic converters, are the main source of the harmonics that affect the performance of the impedance-type distance relays. It was found that, in the presence of harmonics, undesired operation of such type of distance protection will occur, as the distance relay can react improperly and sense faults at zones other than the desired ones and the selectivity of the distance relays will be violated as improper relays will react while those concerned will not. It has been also shown that the fault location and the fault resistance were affecting the impedance seen by the distance relay. The data obtained from the analysis of a three-phase-to-ground fault, in a sample four-bus practical system, was used to study the behavior of the distance relay and to estimate the impedance seen by it. An algorithm, that can be used to calculate the system quantities in the presence of a harmonic source, was suggested.
\end{abstract}

Key words: Power system protection, distance relay, impedance-type distance relay, impedance seen by the distance relay, three-phase-to-ground fault, power transmission ${ }_{2}$ non-linear loads

\section{INTRODUCTION}

Power transmission lines are vital to power systems as they constitute the power systems' backbone. Due to their spreading over long distances and their exposure to outdoor environment, the fault rate of the power transmission lines is much higher than that of the other parts of the power system.

The faults in the power transmission lines result from insulation, electrical, mechanical and thermal faults. These faults are classified as shunt faults and open-circuit faults. The frequency of occurrence of the open-circuit faults is less than that of the shunt faults. Most of the open-circuit faults are often transformed into shunt faults by subsequent events.

Relays for protecting the power transmission lines must react for the several types of shunt faults, including three-phase-to-ground, two-phase-to-ground, single-phase-to-ground and phase-to-phase faults.

The most common protective relays, used to protect the power transmission lines, are the distance relays.

The principle of operation of the distance relay is based on measuring the impedance, at the fundamental frequency, between the relay location and the fault point. This gives the ability to determine if the fault is inside or outside the protected zone. Voltage and current values, measured by the distance relay, are used to calculate the value of the impedance seen by the relay. These voltage and current values contain the fundamental frequency signals and the higher-order harmonics that degrade the quality of the current and voltage waveforms sensed by the impedance relay.

The feeder length protected by the distance relay is normally divided into three zones, covering 85,150 and $225 \%$ of the feeder protected length, respectively. For faults within the first zone of the feeder (within $85 \%$ of the feeder protected length), the protection circuit breakers are ordered to open instantaneously and without any delay. For faults outside this zone (faults at distances greater than $85 \%$ of the feeder protected length) and for faults within the adjoining circuits, the protection circuit breakers are ordered to open after some delays.

The basic characteristics of the distance relay: The distance relay is characterized by having two measuring circuits that measure the feeder current and the feeder voltage at the relaying point. The impedance seen by the relay is calculated as the ratio between the voltage and the current values measured by the relaymeasuring circuits.

The impedance relay will operate when the magnitude of the impedance seen by the relay is less than the relay setting value. This characteristic draws a 


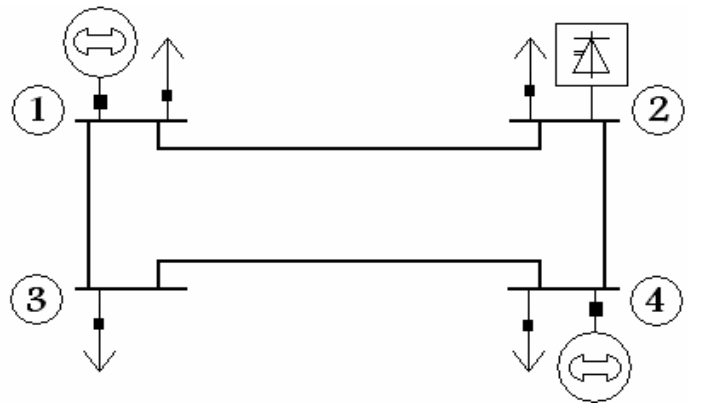

Fig. 1: The practical four-bus sample system

circle with a center at the origin, of the $\mathrm{R}$ and $\mathrm{X}$-axes, and having a radius equal to the relay setting value.

The impedance seen by the distance relay $\left(Z_{R}\right)$ is directly proportional to the distance between the fault location and the relaying-point, $(\alpha)$ and is independent on the type of the fault. If the relaying point is at the beginning of line 1 (near bus 1), of the sample four-bus system, shown in Fig. 1, and a three phase-to-ground fault occurs at distance $(\alpha)$ along line 1-2, the impedance seen by the relay will be:

$$
Z_{R}=\frac{V_{R}}{I_{R}}
$$

As:

$$
\mathrm{V}_{\mathrm{R}}=\mathrm{I}_{\mathrm{R}} \cdot \alpha \cdot \mathrm{Z}_{12}
$$

Thus:

$$
\mathrm{Z}_{\mathrm{R}}=\alpha \cdot \mathrm{Z}_{12}
$$

Here: $V_{R}$ and $I_{R}$ are the voltage and the current values, at the relaying point, respectively. $Z_{12}$ is the impedance of the protected line, (line 1-2).

The sample system and the calculation algorithm: A practical four-bus power system, as shown in Fig. 1, was used as a sample system for the study. The transmission lines were assumed to have per-unit parameters as shown in Table 1. The active power $(\mathrm{P})$, the reactive power $(\mathrm{Q})$ and the voltage for each bus were as shown in Table 2. A nonlinear load (a six-pulse rectifier) having an input power of $50 \mathrm{MW}$, with a power factor of 0.85 , was assumed to be connected to bus 2 .

The base values for the system were assumed to be 100 MVA and $230 \mathrm{kV}$.

The load-flow calculation algorithm is shown in

\begin{tabular}{|c|c|c|c|c|}
\hline $\begin{array}{l}\text { Line, } \\
\text { bus to bus }\end{array}$ & $\begin{array}{l}\mathrm{R} \\
\text { Per unit }\end{array}$ & $\begin{array}{l}\mathrm{X} \\
\text { Per unit }\end{array}$ & $\begin{array}{l}\text { G } \\
\text { Per unit }\end{array}$ & $\begin{array}{l}\text { B } \\
\text { Per unit }\end{array}$ \\
\hline $1-2$ & 0.01008 & 0.05040 & 3.815629 & -19.078144 \\
\hline $1-3$ & 0.00744 & 0.03720 & 5.169561 & -25.847809 \\
\hline $2-4$ & 0.00744 & 0.03720 & 5.169561 & -25.847809 \\
\hline $3-4$ & 0.01272 & 0.06360 & 3.023705 & -15.118528 \\
\hline
\end{tabular}
Fig. 2.
Table 1: Parameters of the system transmission lines

\begin{tabular}{|c|c|c|c|c|c|c|}
\hline \multirow[b]{2}{*}{ Bus } & \multicolumn{2}{|c|}{ Generation } & \multicolumn{2}{|l|}{ Load } & \multirow[b]{2}{*}{$\mathrm{V}$, per unit } & \multirow[b]{2}{*}{ Remarks } \\
\hline & $\begin{array}{c}\text { P, } \\
\text { MW }\end{array}$ & $\begin{array}{c}\text { Q, } \\
\text { Mvar }\end{array}$ & $\begin{array}{r}\text { P, } \\
\text { MW }\end{array}$ & $\begin{array}{c}\text { Q, } \\
\text { Mvar }\end{array}$ & & \\
\hline 1 & - & - & 50 & 30.99 & $1.00 \angle 0^{\circ}$ & Slack bus \\
\hline 2 & 0 & 0 & 170 & 105.35 & $1.00 \angle 0^{\circ}$ & Load bus (inductive) \\
\hline 3 & 0 & 0 & 200 & 123.94 & $1.00 \angle 0^{\circ}$ & Load bus (inductive) \\
\hline 4 & 318 & - & 80 & 49.58 & $1.00 \angle 0^{\circ}$ & Voltage controlled \\
\hline
\end{tabular}

Table 2: The active power $(\mathrm{P})$, the reactive power $(\mathrm{Q})$ and the voltage (V) of the system buses

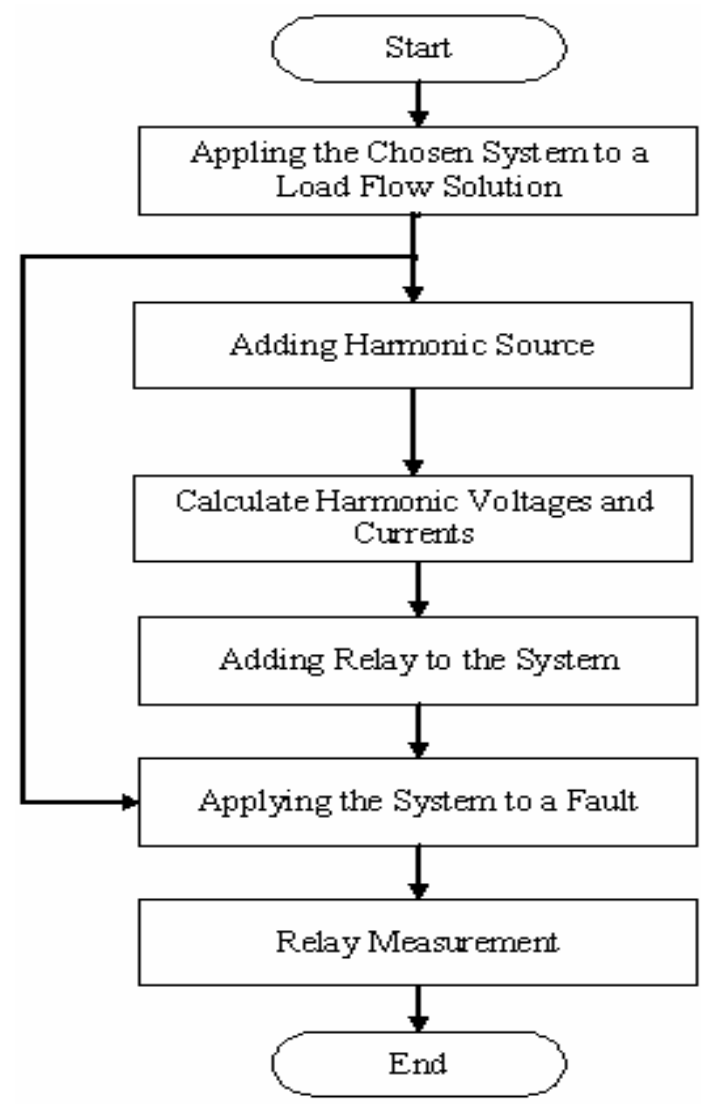

Fig. 2: The load-flow calculation algorithm

The fundamental transmission line currents, flowing between bus $\mathrm{i}$ and bus $\mathrm{j}$, were calculated using the equation:

$$
I_{i j}=\left(V_{i}-V_{j}\right) \cdot Y_{i j}
$$


Am. J. of Appl. Sci., 6 (4): 788-796, 2009

Where:

$\mathrm{V}_{\mathrm{i}}$ and $\mathrm{V}_{\mathrm{j}}=$ Fundamental voltages at bus $\mathrm{i}$ and bus $\mathrm{j}$, respectively

$\mathrm{Y}_{\mathrm{ij}} \quad=$ Admittance to the fundamental component, between bus $\mathrm{i}$ and bus $\mathrm{j}$

The results of the system load flow solution are shown in Table 3-5. The system branch currents are shown in Table 6.

The system bus admittance matrix [ $\left.\mathrm{Y}_{\text {bus }}\right]$ and the load impedances, corresponding to the harmonic under consideration, were calculated taking into account the following facts:the reactance of any inductive element is proportional to the order of the harmonic, h, or:

$$
X_{L(h)}=j \cdot \omega_{0} \cdot h \cdot L
$$

The resistance of any element remains fixed and doesn't depend on the harmonic order.

Taking into consideration these two facts, the impedances of the loads connected to the system buses were calculated, as below:

For of the load connected to bus 1:

$$
\begin{aligned}
& \theta_{1}=\tan ^{-1}\left(\frac{\mathrm{Q}_{1}}{\mathrm{P}_{1}}\right)=\tan ^{-1}\left(\frac{0.31}{0.5}\right)=31.79^{\circ} \\
& \mathrm{S}_{1}=\frac{\mathrm{P}_{1}}{\cos \left(\theta_{1}\right)}=\frac{0.5}{\cos \left(31.79^{\circ}\right)}=0.588 \mathrm{p} \cdot \mathrm{u} \\
& \mathrm{Z}_{\mathrm{L} 1}=\frac{\left(\mathrm{V}_{1}\right)^{2}}{\mathrm{~S}_{1}}=\frac{(1)^{2}}{0.588}=1.699 \mathrm{p} \cdot \mathrm{u} \\
& \mathrm{X}_{\mathrm{L} 1}=\mathrm{Z}_{\mathrm{L} 1} \cdot \sin \left(\theta_{1}\right)=1.699 \sin \left(31.79^{\circ}\right)=0.8955 \mathrm{p} \cdot \mathrm{u} \\
& \mathrm{R}_{\mathrm{L} 1}=\mathrm{Z}_{\mathrm{L} 1} \cdot \cos \left(\theta_{1}\right)=1.699 \cos \left(31.79^{\circ}\right)=1.444 \mathrm{p} \cdot \mathrm{u}
\end{aligned}
$$

or:

$$
\begin{aligned}
Z_{L 1(h)} & =R_{L 1}+j \cdot X_{L 1} \cdot h \\
& =1.444+j 0.8955 h
\end{aligned}
$$

In the same method, the impedances of the loads connected to the other buses were found to be:

The impedance of the load connected to bus 2:

$$
\begin{aligned}
Z_{\mathrm{L} 2(\mathrm{~h})} & =\mathrm{R}_{\mathrm{L} 2}+\mathrm{j} \cdot \mathrm{X}_{\mathrm{L} 2} \cdot \mathrm{h} \\
& =0.4102+\mathrm{j} 0.2542 \mathrm{~h}
\end{aligned}
$$

The impedance of the load connected to bus 3:

$$
\begin{aligned}
Z_{L 3(h)} & =R_{L 3}+j \cdot X_{L 3} \cdot h \\
& =0.33+j 0.211 h
\end{aligned}
$$

Table 3: The bus active and reactive powers and voltage magnitudes

\begin{tabular}{lccll}
\hline & \multicolumn{2}{c}{ Load } & $\begin{array}{l}\text { Voltage } \\
\text { magnitude, } \\
\text { per unit }\end{array}$ & $\begin{array}{l}\text { Voltage } \\
\text { angle }\end{array}$ \\
Bus No. & P, MW & Q, Mvar & 1.0000 & $0^{\circ}$ \\
\hline 1 & 50 & 30.99 & 0.98242 & $-0.97612^{\circ}$ \\
2 & 170 & 105.35 & 0.96900 & $-1.8722^{\circ}$ \\
3 & 200 & 123.94 & 1.02000 & $1.5231^{\circ}$ \\
4 & 80 & 49.58 & & \\
\hline
\end{tabular}

Table 4: The bus sending and receiving active and reactive powers

\begin{tabular}{llllll}
\hline & & \multicolumn{2}{c}{ Sending } & \multicolumn{2}{c}{ Receiving } \\
From & To & P, & Q, & P, & Q, \\
bus & bus & MW & Mvar & MW & Mvar \\
\hline 1 & 2 & 38.692 & 22.298 & -38.465 & -31.236 \\
1 & 3 & 98.118 & 61.212 & -97.086 & -63.569 \\
2 & 4 & -131.540 & -74.114 & 133.250 & 74.920 \\
3 & 4 & -102.910 & -60.371 & 104.750 & 56.930 \\
\hline
\end{tabular}

Table 5: Generating buses active and reactive powers

\begin{tabular}{llll}
\hline & & Generation & \\
Bus No. & P, MW & Q, Mvar & voltage \\
\hline 4 & 318.00 & 181.43 & 1.02 \\
1 & 186.81 & 114.50 & 1.00 \\
\hline
\end{tabular}

Table 6: Transmission line currents

\begin{tabular}{ll}
\hline Branch current & Per unit value \\
\hline $\mathrm{I}_{12}$ & $-0.38692+0.27423 \mathrm{i}$ \\
$\mathrm{I}_{13}$ & $-0.98118+0.65087 \mathrm{i}$ \\
$\mathrm{I}_{42}$ & $-1.3265+0.73903 \mathrm{i}$ \\
$\mathrm{I}_{43}$ & $-1.0432+0.59565 \mathrm{i}$ \\
\hline
\end{tabular}

The impedance of the load connected to bus 4 :

$$
\begin{aligned}
Z_{L 4(h)} & =R_{L 4}+j \cdot X_{L 4} \cdot h \\
= & 0.9395+j 0.5823 h
\end{aligned}
$$

As the system was balanced, the positive and the negative sequence equivalent circuits were identical and were as in Fig. 3.

From this equivalent circuit, the system bus admittance matrix can be built, and will be:

$$
Y_{\text {bus (h) }}=\left[\begin{array}{cccc}
Y_{11(\mathrm{~h})} & Y_{12(\mathrm{~h})} & Y_{13(\mathrm{~h})} & Y_{14(\mathrm{~h})} \\
Y_{21(\mathrm{~h})} & \mathrm{Y}_{22(\mathrm{~h})} & \mathrm{Y}_{23(\mathrm{~h})} & \mathrm{Y}_{24(\mathrm{~h})} \\
\mathrm{Y}_{31(\mathrm{~h})} & \mathrm{Y}_{32(\mathrm{~h})} & \mathrm{Y}_{33(\mathrm{~h})} & \mathrm{Y}_{34(\mathrm{~h})} \\
\mathrm{Y}_{41(\mathrm{~h})} & \mathrm{Y}_{42(\mathrm{~h})} & \mathrm{Y}_{43(\mathrm{~h})} & \mathrm{Y}_{44(\mathrm{~h})}
\end{array}\right]
$$

To calculate the harmonic bus voltages, the nonlinear load (the six-pulse rectifier) was replaced by an equivalent current source, injecting a current with a magnitude and a frequency equal to that of the harmonic under consideration. Table 7 shows the relative contents of the different current harmonics 


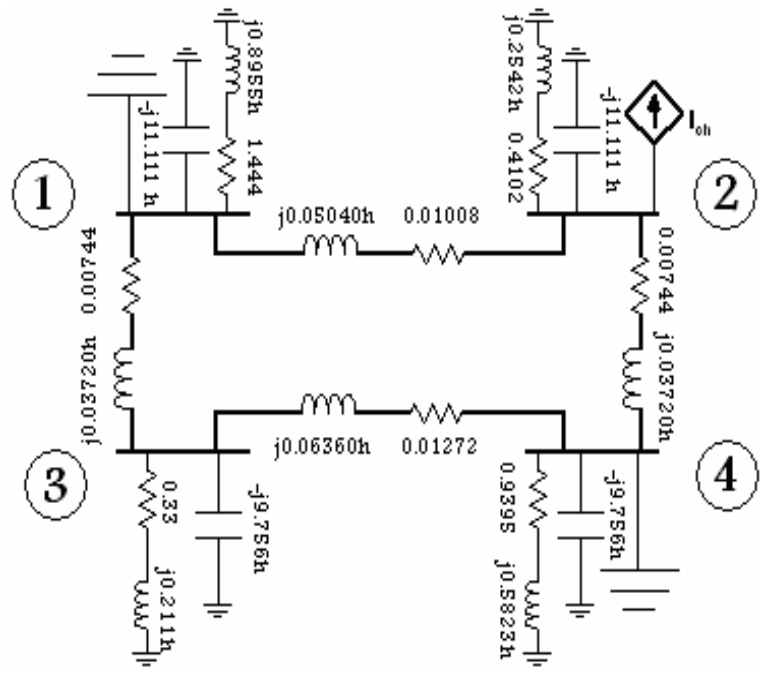

Fig. 3: The system positive-sequence equivalent circuit

Table 7: The relative contents of the current harmonics for the sixpulse rectifier

\begin{tabular}{llll}
\hline $\mathrm{h}$ & $\% \mathrm{I}_{\mathrm{C}} \mathrm{h}$ & $\mathrm{I}_{\mathrm{ch}}$ & $\theta_{\mathrm{h}}$ \\
\hline 5 & 0.2 & 0.1198 & $-\pi$ \\
7 & 0.143 & 0.0856 & 0 \\
11 & 0.091 & 0.0545 & $-\pi$ \\
13 & 0.077 & 0.0461 & 0 \\
17 & 0.059 & 0.0353 & $-\pi$ \\
19 & 0.053 & 0.0317 & 0 \\
23 & 0.043 & 0.0257 & $-\pi$ \\
25 & 0.04 & 0.0239 & 0 \\
29 & 0.034 & 0.0204 & $-\pi$ \\
\hline
\end{tabular}

(as compared to the rectifier fundamental input current) for the case of the six-pulse rectifier, under consideration.

The magnitudes of the current harmonics were calculated from their relative contents, after calculating the fundamental rectifier input current, as:

$$
\begin{aligned}
& \mathrm{I}_{\mathrm{C}}=\frac{\mathrm{P}}{\left|\mathrm{V}_{2}\right| \cdot \cos \phi}=\frac{0.5}{0.982 \times 0.85}=0.599 \mathrm{p} \cdot \mathrm{u} \\
& \mathrm{I}_{\mathrm{ch}}=\left(\left.\% \mathrm{I}_{\mathrm{C}}\right|_{\mathrm{h}}\right) \times \mathrm{I}_{\mathrm{C}}
\end{aligned}
$$

Where:

$\mathrm{I}_{\mathrm{c}}$ : The magnitude of the fundamental rectifier input current

$I_{\text {ch }}$ : The magnitude of the rectifier input current harmonic with order $\mathrm{h}$

The phase angle of each rectifier input current harmonic was calculated by the equation:

$$
\gamma_{\mathrm{h}}=\mathrm{h} \cdot \gamma_{1}-\theta_{\mathrm{h}}
$$

Where:

$\gamma_{1}=$ Phase angle of the fundamental rectifier input current

$\theta_{\mathrm{h}}=$ Phase angle of the rectifier input current harmonic with order ${ }^{\mathrm{h}}$

The harmonic voltages at each bus were calculated by the equation:

$$
\left[\begin{array}{c}
\left.\mathrm{V}_{1}\right|_{\mathrm{h}} \\
\left.\mathrm{V}_{2}\right|_{\mathrm{h}} \\
\left.\mathrm{V}_{3}\right|_{\mathrm{h}} \\
\left.\mathrm{V}_{4}\right|_{\mathrm{h}}
\end{array}\right]=\left[\begin{array}{l}
\mathrm{Z}_{\text {bus }(\mathrm{h})}, \text { where } \\
\mathrm{h}=5,9,11, \ldots, 29
\end{array}\right] \cdot\left[\begin{array}{c}
0 \\
\left.\mathrm{I}_{\mathrm{C}}\right|_{\mathrm{h}} \\
0 \\
0
\end{array}\right]
$$

As the Fundamental and the harmonic voltages, for each bus were calculated, the total bus voltages can be found using the superposition principle.

The harmonic transmission line currents flowing between bus $\mathrm{i}$ and bus $\mathrm{j}$ were calculated, using the equation:

$$
\left.\mathrm{I}_{\mathrm{ij}}\right|_{\mathrm{h}}=\left(\left.\mathrm{V}_{\mathrm{i}}\right|_{\mathrm{h}}-\left.\mathrm{V}_{\mathrm{j}}\right|_{\mathrm{h}}\right) \cdot \mathrm{Y}_{\mathrm{ij}(\mathrm{h})}
$$

Where:

$\mathrm{V}_{\mathrm{i}} \mathrm{l}_{\mathrm{h}}$ and $\mathrm{V}_{\mathrm{j}} \mathrm{l}_{\mathrm{h}}=$ The magnitudes of the harmonic voltages of order $h$ at buses $i$ and $j$, respectively

$Y_{\mathrm{ij}(\mathrm{h})}$

$=$ The admittance to the harmonic of order $\mathrm{h}$ between bus $\mathrm{i}$ and bus $\mathrm{j}$

The total transmission line current was found using the superposition principle, or:

$$
\begin{aligned}
\mathrm{I}_{\mathrm{ij}}(\mathrm{t})= & \sqrt{2} \cdot \mathrm{I}_{\mathrm{rmsl}} \cdot \cos \left(\omega_{1} \cdot \mathrm{t}+\gamma_{1}\right)+ \\
& \sqrt{2} \cdot \mathrm{I}_{\mathrm{rms} 5} \cdot \cos \left(\omega_{5} \cdot \mathrm{t}+\gamma_{5}\right)+ \\
& \sqrt{2} \cdot \mathrm{I}_{\mathrm{rms} 7} \cdot \cos \left(\omega_{5} \cdot \mathrm{t}+\gamma_{5}\right)+\ldots
\end{aligned}
$$

The fault calculation: It is known that, in case of a three-phase-to-ground fault at any bus (bus P), the fault current, flowing to ground, can be estimated by:

$$
I_{P}^{F}=\frac{V_{P}^{(0)}}{Z_{P P}}
$$

Where:

$\mathrm{V}_{\mathrm{p}}^{(0)}=$ Voltage of bus $\mathrm{P}$, before the fault is occurring

$\mathrm{Z}_{\mathrm{pp}}=$ Self-impedance of bus $\mathrm{P}$

To calculate the fault current, due to a three-phaseto-ground fault, at a given point, a fifth bus located at 
the fault point has to be added to the system. The system bus admittance matrix has to be reformulated to take into account the new added bus.

As the fault was assumed to occur at the line connecting buses 1 and 2 , and at a distance $\alpha$ from bus 1 , the voltage at the new bus before the fault occurring, will be:

$$
\mathrm{V}_{5}^{(0)}=\mathrm{V}_{1}^{(0)}-\mathrm{I}_{12}^{(0)} \cdot \alpha \cdot \mathrm{Z}_{12}
$$

as:

$$
I_{12}^{(0)}=\frac{V_{1}^{(0)}-V_{2}^{(0)}}{Z_{12}}
$$

or:

$$
\mathrm{V}_{5}^{(0)}=\mathrm{V}_{1}^{(0)}-\alpha\left(\mathrm{V}_{1}^{(0)}-\mathrm{V}_{2}^{(0)}\right)
$$
thus:

This equation is valid for all harmonic voltages,

$$
\left.\mathrm{V}_{5}^{(0)}\right|_{\mathrm{h}}=\left.\mathrm{V}_{1}^{(0)}\right|_{\mathrm{h}}-\alpha\left(\left.\mathrm{V}_{1}^{(0)}\right|_{\mathrm{h}}-\left.\mathrm{V}_{2}^{(0)}\right|_{\mathrm{h}}\right)
$$

where, $\mathrm{V}_{\mathrm{p}}{ }^{(0)} \mathrm{I}_{\mathrm{h}}$ is Harmonic voltage, of order $\mathrm{h}$, at bus $\mathrm{i}$, before the fault is occurring.

The bus voltages during the fault were calculated as:

$$
\left[\begin{array}{l}
\mathrm{V}_{1} \\
\mathrm{~V}_{2} \\
\mathrm{~V}_{3}^{\mathrm{f}} \\
\mathrm{V}_{4} \\
\mathrm{~V}_{5}
\end{array}\right]^{\mathrm{f}}=\left[\begin{array}{c}
\mathrm{V}_{1} \\
\mathrm{~V}_{2} \\
\mathrm{~V}_{3}^{(0)} \\
\mathrm{V}_{4} \\
\mathrm{~V}_{5}
\end{array}\right]^{\mathrm{t}}+\left[\begin{array}{l}
\mathrm{V}_{1} \\
\mathrm{~V}_{2} \\
\mathrm{~V}_{3} \\
\mathrm{~V}_{4} \\
\mathrm{~V}_{5}
\end{array}\right]^{\mathrm{t}}
$$

Where:

$$
\left[\begin{array}{c}
\mathrm{V}_{1} \\
\mathrm{~V}_{2} \\
\mathrm{~V}_{3} \\
\mathrm{~V}_{4} \\
\mathrm{~V}_{5}
\end{array}\right]^{\mathrm{t}}=\left[\begin{array}{lllll}
\mathrm{Z}_{11} & \mathrm{Z}_{12} & \mathrm{Z}_{13} & \mathrm{Z}_{14} & \mathrm{Z}_{15} \\
\mathrm{Z}_{21} & \mathrm{Z}_{22} & \mathrm{Z}_{23} & \mathrm{Z}_{24} & \mathrm{Z}_{25} \\
\mathrm{Z}_{31} & \mathrm{Z}_{32} & \mathrm{Z}_{33} & \mathrm{Z}_{34} & \mathrm{Z}_{35} \\
\mathrm{Z}_{41} & \mathrm{Z}_{42} & \mathrm{Z}_{43} & \mathrm{Z}_{44} & \mathrm{Z}_{45} \\
\mathrm{Z}_{51} & \mathrm{Z}_{52} & \mathrm{Z}_{53} & \mathrm{Z}_{54} & \mathrm{Z}_{55}
\end{array}\right] \cdot\left[\begin{array}{c}
0 \\
0 \\
0 \\
0 \\
-\mathrm{I}_{5}^{\mathrm{F}}
\end{array}\right]
$$

and:

$$
\mathrm{I}_{5}^{\mathrm{F}}=\frac{\mathrm{V}_{5}^{(0)}}{\mathrm{Z}_{55}}
$$

These equations were used to calculate the buses harmonic voltages for all the harmonics under consideration.

The R.M.S values of the bus voltages and the line currents (including that measured by the distance relay at bus 5), were calculated as:

$$
\begin{aligned}
& \left|\mathrm{V}_{\mathrm{rms}}\right|=\sqrt{\mathrm{V}_{\mathrm{i}}^{2}+\left(\left|\mathrm{V}_{\mathrm{i}}\right|_{\mathrm{h}=5}\right)^{2}+\left(\mid \mathrm{V}_{\mathrm{i}} \|_{\mathrm{h}=7}\right)^{2}+\ldots} \\
& \left|\mathrm{I}_{\mathrm{rms}}\right|=\sqrt{\mathrm{I}_{\mathrm{i}}^{2}+\left(\left|\mathrm{I}_{\mathrm{i}}\right|_{\mathrm{h}=5}\right)^{2}+\left(\mid \mathrm{I}_{\mathrm{i}} \|_{\mathrm{h}=7}\right)^{2}+\ldots}
\end{aligned}
$$

For the purpose of calculating the impedance seen by the distance relay, these values was considered as vectors having phase angles equal to that of their fundamentals, or:

$$
\begin{aligned}
& \mathrm{V}_{\mathrm{rms}}=\left|\mathrm{V}_{\mathrm{rms}}\right| \angle \theta \\
& \mathrm{I}_{\mathrm{rms}}=\left|\mathrm{I}_{\mathrm{rms}}\right| \angle \theta
\end{aligned}
$$

The performance of the impedance-type distance relay: As known, the operation of the impedance-type distance relay is based on comparing the value of the impedance seen by the relay with the relay setting, for a certain protection zone. The relay provides a trip signal when the impedance seen by the relay is less than or equal to its setting. The transformation ratios of the Current Transformers (CTs) and Voltage Transformers (VTs), included in the relay circuit, are taken into consideration as multiplication factors when determining the relay adjustments.

For studying the effect of the harmonics on the performance of the impedance-type distance relay, a relay of this type was assumed to be installed at bus 1 . Three-phase- to-ground faults were also assumed to occur at different locations within the sample circuit.

The impedance seen by the relay was calculated as:

$$
Z_{\text {relay }}=\frac{V_{\text {rms }}}{I_{\text {rms }}}
$$

where, $V_{m s}$ and $I_{m s}$ are those including the voltage and the current harmonics measured by the distance relay, as defined by Eq. 18-21.

The response of the distance relay was also checked by the sign of the torque, produced by relay mechanism, as defined by the equation:

$$
\mathrm{T}=\mathrm{K}_{1} \cdot \mathrm{I}^{2}-\mathrm{K}_{2} \cdot \mathrm{V}^{2}-\mathrm{K}_{3}
$$


If the sign of this torque is positive, the relay will produce a tripping signal, while if this torque is negative or zero the relay will not produce a tripping signal.

The impedance seen by the distance relays, located at the end of the line connecting bus 1 and 2, for faults at different locations, with harmonic injection (a) and without harmonic injection (b), are shown in Fig. 4-11.

The impedance seen by the distance relay as a function of the fault location, with and without harmonic injection, is shown in the Fig. 11.

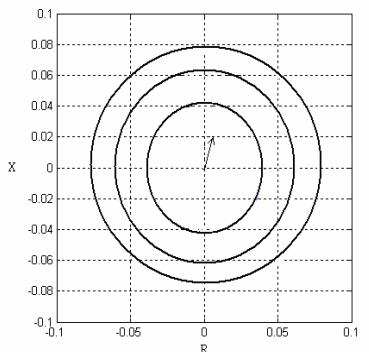

(a)

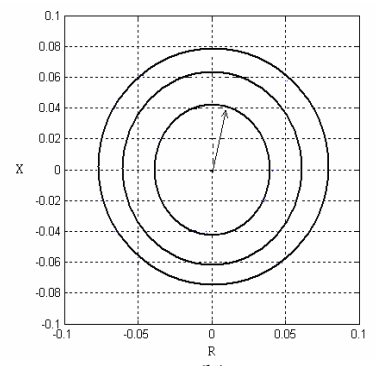

(b)
Fig. 4: The impedance seen by the relay for a fault at $25 \%$ far from bus 1

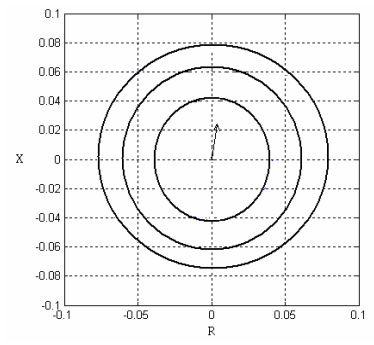

(a)

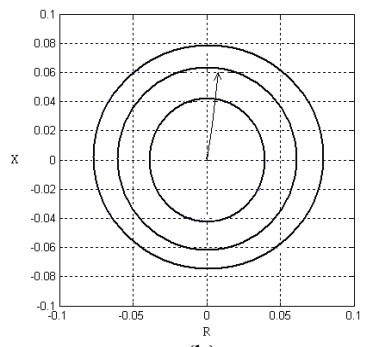

(b)
Fig. 5: The impedance seen by the relay for a fault at $50 \%$ far from bus 1

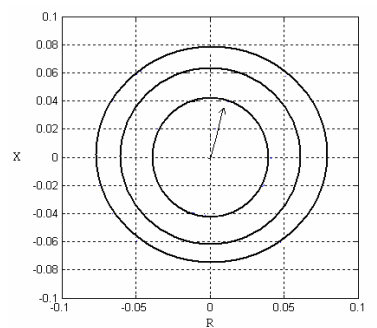

(a)

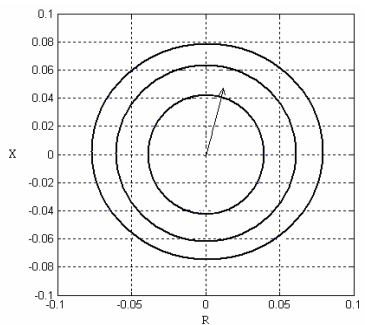

(b)
Fig. 6: The impedance seen by the relay for a fault at $70 \%$ far from bus 1
The torque produced by the same relay (for different values of the constants $\mathrm{K}_{1}, \mathrm{~K}_{2}$ and $\mathrm{K}_{3}$ ) and for faults at different locations, are shown in the Table 8-14.

From the previously said, it can be concluded that, in the presence of harmonics:

- The distance relay can react improperly and sense faults at zones other than the desired ones

- The selectivity of the distance relays can be violated as improper relays will react while those concerned will not

- At the same time, other than the desired relay will react. This will lead to disconnect other healthy lines

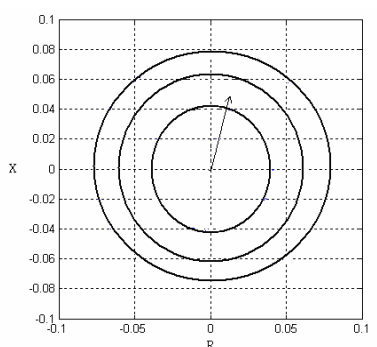

(a)

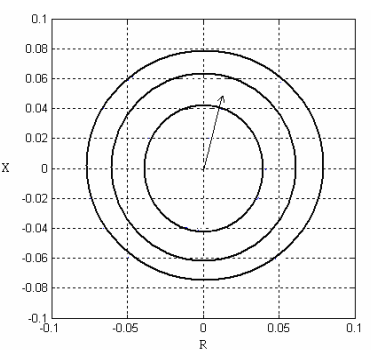

(b)
Fig. 7: The impedance seen by the relay for a fault at $95 \%$ far from bus 1

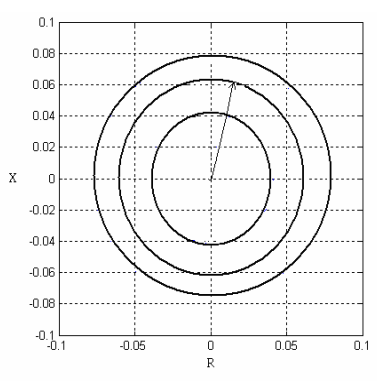

(a)

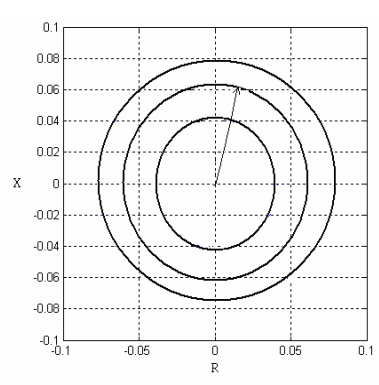

(b)
Fig. 8: The impedance seen by the relay for a fault at $115 \%$ far from bus 1

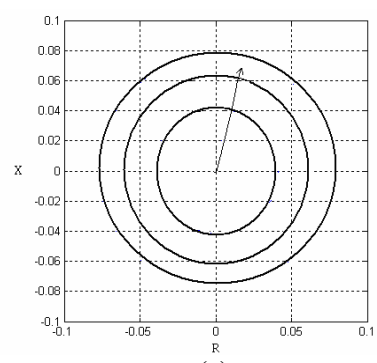

(a)

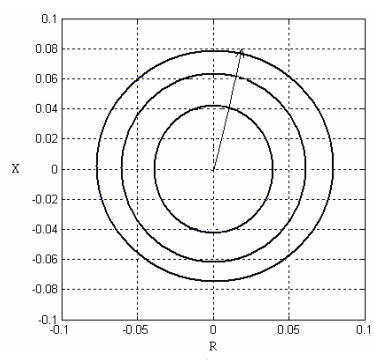

(b)
Fig. 9: The impedance seen by the relay for a fault at $130 \%$ far from bus 1 
Am. J. of Appl. Sci., 6 (4): 788-796, 2009

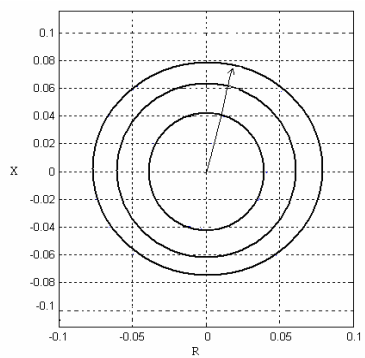

(a)

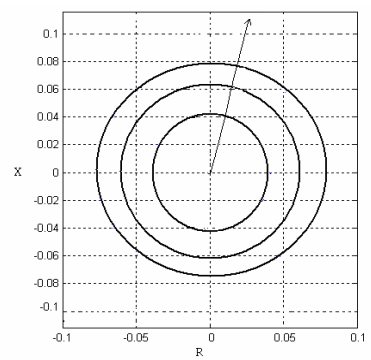

(b)
Fig. 10: The impedance seen by the relay for a fault at $140 \%$ far from bus 1

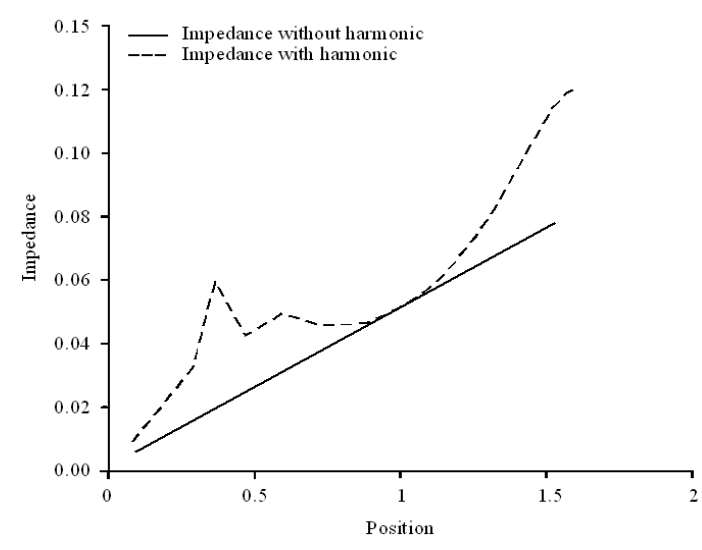

Fig. 11: The impedance seen by the relay as a function of the fault location, with and without harmonic injection

Table 8: The torque produced by the relay for a fault at $25 \%$ far from bus 1

\begin{tabular}{lll}
\hline & Torque without harmonic & Torque with harmonic \\
\hline $\mathrm{T}_{1}$ & 7.1349 & 2.5002 \\
$\mathrm{~T}_{2}$ & 8.4562 & 6.4389 \\
$\mathrm{~T}_{3}$ & 8.8367 & 7.5732 \\
\hline
\end{tabular}

Table 9: The torque produced by the relay for a fault at $50 \%$ far from bus 1

\begin{tabular}{lll}
\hline & Torque without harmonic & Torque with harmonic \\
\hline $\mathrm{T}_{1}$ & 5.2316 & -9.7820 \\
$\mathrm{~T}_{2}$ & 7.0947 & 0.4701 \\
$\mathrm{~T}_{3}$ & 7.6313 & 3.4228 \\
\hline
\end{tabular}

Effect of the fault location and the fault resistance on the impedance seen by the distance relay: In this study, a three-phase-to-ground-fault was assumed to occur at a point, far at distance $\alpha$ from bus 1 , in the line connecting buses 1 and 2 in the sample system shown in Fig. 1. The line was assumed to be protected by a distance relay, located at bus 1 end of this line.
Table 10: The torque produced by the relay for a fault at $70 \%$ far from bus 1

\begin{tabular}{lll}
\hline & Torque without harmonic & Torque with harmonic \\
\hline $\mathrm{T}_{1}$ & 1.6197 & -2.9006 \\
$\mathrm{~T}_{2}$ & 4.5591 & 2.5623 \\
$\mathrm{~T}_{3}$ & 5.4057 & 4.1357 \\
\hline
\end{tabular}

Table 11: The torque produced by the relay for a fault at $95 \%$ far from bus 1

\begin{tabular}{lll}
\hline & Torque without harmonic & Torque with harmonic \\
\hline $\mathrm{T}_{1}$ & -2.0970 & -2.1827 \\
$\mathrm{~T}_{2}$ & 1.9084 & 1.8706 \\
$\mathrm{~T}_{3}$ & 3.0620 & 3.0379 \\
\hline
\end{tabular}

Table 12: The torque produced by the relay for a fault at $115 \%$ far from bus 1

\begin{tabular}{lll}
\hline & Torque without harmonic & Torque with harmonic \\
\hline $\mathrm{T}_{1}$ & -4.0719 & -5.2283 \\
$\mathrm{~T}_{2}$ & 0.3243 & -0.1860 \\
$\mathrm{~T}_{3}$ & 1.5903 & 1.2661 \\
\hline
\end{tabular}

Table 13: The torque produced by the relay for a fault at $130 \%$ far from bus 1

\begin{tabular}{lll}
\hline & Torque without harmonic & Torque with harmonic \\
\hline $\mathrm{T}_{1}$ & -4.9290 & -9.1814 \\
$\mathrm{~T}_{2}$ & -0.4936 & -2.3774 \\
$\mathrm{~T}_{3}$ & 0.7838 & -0.4178 \\
\hline
\end{tabular}

Table 14: The torque produced by the relay for a fault at $145 \%$ far from bus 1

\begin{tabular}{lll}
\hline & Torque without harmonic & Torque with harmonic \\
\hline $\mathrm{T}_{1}$ & -5.1983 & -16.9369 \\
$\mathrm{~T}_{2}$ & -0.8746 & -6.0777 \\
$\mathrm{~T}_{3}$ & 0.3706 & -2.9502 \\
\hline
\end{tabular}

To calculate the fault current, due to this fault, a fifth bus, located at the fault location, was added to the system.

The fault current, $\mathrm{I}_{\mathrm{f}}$, will be:

$$
I_{f}=\frac{V_{5}^{(0)}}{Z_{55}+R_{f}}
$$

but:

$$
\mathrm{V}_{5}^{(0)}=\mathrm{V}_{1}^{(0)}-\alpha\left(\mathrm{V}_{1}^{(0)}-\mathrm{V}_{2}^{(0)}\right)
$$

thus:

$$
I_{f}=\frac{V_{1}^{(0)}(1-\alpha)+\alpha V_{2}^{(0)}}{Z_{55}+R_{f}}
$$

In this equation, $V_{i}^{(0)}$ is the pre-fault voltage of bus (i) and $\alpha$ is the ratio of the line length from the relay to the fault point.

The current, $\mathrm{I}_{\mathrm{R}}$, at the relaying point is: 


$$
\mathrm{I}_{\mathrm{R}} \approx \frac{\mathrm{V}_{1}^{\mathrm{f}}-\mathrm{V}_{5}^{\mathrm{f}}}{\alpha \cdot Z_{12}}
$$

but:

$$
\mathrm{V}_{1}^{\mathrm{f}}=\mathrm{V}_{1}^{(0)}+\mathrm{V}_{1}^{\mathrm{t}}
$$

and:

$$
\mathrm{V}_{5}^{\mathrm{f}}=\mathrm{V}_{5}^{(0)}+\mathrm{V}_{5}^{\mathrm{t}}
$$

thus:

$$
\mathrm{I}_{\mathrm{R}} \approx \frac{\mathrm{V}_{1}^{(0)}+\mathrm{V}_{1}^{\mathrm{t}}-\left(\mathrm{V}_{5}^{(0)}+\mathrm{V}_{5}^{\mathrm{t}}\right)}{\alpha \cdot Z_{12}}
$$

or:

$$
\mathrm{I}_{\mathrm{R}} \approx \frac{\mathrm{V}_{1}^{(0)}-\mathrm{Z}_{15} \cdot \mathrm{I}_{\mathrm{f}}-\left[\mathrm{V}_{5}^{(0)}-\mathrm{Z}_{55} \cdot \mathrm{I}_{\mathrm{f}}\right]}{\alpha \cdot \mathrm{Z}_{12}}
$$

Substituting Eq. 25 and 26 in this equation, it was found that:

$$
\mathrm{I}_{\mathrm{R}} \approx \frac{\alpha\left(\mathrm{V}_{1}^{(0)}-\mathrm{V}_{2}^{(0)}\right)\left(\mathrm{Z}_{55}+\mathrm{R}_{\mathrm{f}}\right)+\left(\mathrm{Z}_{55}-\mathrm{Z}_{15}\right)\left[\mathrm{V}_{1}^{(0)}(1-\alpha)+\alpha \mathrm{V}_{2}^{(0)}\right]}{\alpha \cdot \mathrm{Z}_{12} \cdot\left(\mathrm{Z}_{55}+\mathrm{R}_{\mathrm{f}}\right)}
$$

For the case of $\mathrm{V}_{1}^{(0)}=\mathrm{V}_{2}^{(0)} \approx 1 \mathrm{p}$.u

$$
I_{R} \approx \frac{\left(Z_{55}-Z_{15}\right)}{\alpha \cdot Z_{12} \cdot\left(Z_{55}+R_{f}\right)}
$$

Assuming that the distance relay was at distance $\mathrm{P}$ from bus 1, the voltage of the distance relay will be:

$$
\mathrm{V}_{\mathrm{R}}=\mathrm{V}_{1}-\mathrm{I}_{\mathrm{R}} \cdot \mathrm{P} \cdot \mathrm{Z}_{12}
$$

Applying Eq. 16 and 32, we find that:

$$
\mathrm{V}_{\mathrm{R}}=\mathrm{V}_{1}^{(0)}-\mathrm{I}_{\mathrm{f}} \cdot \mathrm{Z}_{15}-\mathrm{I}_{\mathrm{R}} \cdot \mathrm{P} \cdot \mathrm{Z}_{12}
$$

Or in p.u:

$$
\begin{gathered}
\mathrm{V}_{\mathrm{R}}=1-\mathrm{I}_{\mathrm{f}} \cdot \mathrm{Z}_{15}-\mathrm{I}_{\mathrm{R}} \cdot \mathrm{P} \cdot \mathrm{Z}_{12} \\
\mathrm{~V}_{\mathrm{R}}=1-\frac{\mathrm{Z}_{15}}{\mathrm{Z}_{55}+\mathrm{R}_{\mathrm{f}}}-\frac{\left(\mathrm{Z}_{55}-\mathrm{Z}_{15}\right) \cdot \mathrm{P} \cdot \mathrm{Z}_{12}}{\alpha \cdot \mathrm{Z}_{12} \cdot\left(\mathrm{Z}_{55}+\mathrm{R}_{\mathrm{f}}\right)} \\
\mathrm{V}_{\mathrm{R}}=\frac{\alpha \cdot\left(\mathrm{Z}_{55}+\mathrm{R}_{\mathrm{f}}\right)-\mathrm{Z}_{15} \cdot \alpha-\left(\mathrm{Z}_{55}-\mathrm{Z}_{15}\right) \cdot \mathrm{P}}{\alpha \cdot\left(\mathrm{Z}_{55}+\mathrm{R}_{\mathrm{f}}\right)}
\end{gathered}
$$

or:

$$
\mathrm{V}_{\mathrm{R}}=\frac{\mathrm{Z}_{55} \cdot(\alpha-\mathrm{P})+\mathrm{R}_{\mathrm{f}} \cdot \alpha+\mathrm{Z}_{15}(\mathrm{P}-\alpha) \cdot \mathrm{P}}{\alpha \cdot\left(\mathrm{Z}_{55}+\mathrm{R}_{\mathrm{f}}\right)}
$$

The impedance seen by the distance relay can be determined using Eq. 32 and 36, or:

$Z_{R}=\frac{V_{R}}{I_{R}}=\frac{Z_{12} \cdot\left[Z_{55} \cdot(\alpha-P)+R_{f} \cdot \alpha+Z_{15} \cdot(P-\alpha)\right]}{\left(Z_{55}-Z_{15}\right)}$

For the case that $\mathrm{P} \approx 0$, or the distance relay was very close to bus 1 , thus:

$$
Z_{R}=\frac{Z_{12} \cdot Z_{55} \cdot \alpha+Z_{12} \cdot R_{f} \cdot \alpha-Z_{12} \cdot Z_{15} \cdot \alpha}{\left(Z_{55}-Z_{15}\right)}
$$

As the line resistance was small and can be neglected, thus:

$Z_{12}=j . X_{12}$ and $Z_{55}=j . X_{55}$

thus:

$$
Z_{R}=\frac{X_{12} \cdot R_{f} \alpha}{\left(X_{55}-X_{15}\right)}+j \cdot X_{12} \cdot \alpha
$$

Or the resistance seen by the relay was:

$$
\mathrm{R}_{\mathrm{R}}=\frac{\mathrm{X}_{12} \cdot \mathrm{R}_{\mathrm{f}} \alpha}{\left(\mathrm{X}_{55}-\mathrm{X}_{15}\right)}
$$

And the reactance seen by the relay was:

$$
\mathrm{X}_{\mathrm{R}}=\mathrm{X}_{12} \cdot \alpha
$$

These equations indicate that the fault location $(\alpha)$ and the fault resistance $\left(\mathrm{R}_{\mathrm{f}}\right)$ were influencing the value of the impedance seen by the distance relay and these two factors will cause under-reaching or over-reaching in the operation of the distance relay.

\section{CONCLUSION}

An algorithm for computing the bus voltages and the line currents, in the presence of a harmonic source, was presented. This algorithm was used to calculate the impedance seen by the impedance-type distance relay, in case of three-phase-to-ground fault, and in the presence of a harmonic source. 
A practical four-bus power system was used as a sample system for the study. Detailed analysis for the impedance seen by the distance relay, for different fault locations, was provided.

It has been found that in the presence of harmonics, the distance relay will react improperly and sense faults at zones other than the desired ones. This will violate the selectivity of the distance protection, as improper relays will react while those concerned will not, which will cause disconnection of healthy lines. It has been, also, shown that the fault location and the fault resistance were affecting the impedance seen by the distance relay.

\section{REFERENCES}

1. Xia, Y.Q., K.K. Li and A.K. David, 1994. Adaptive relay setting for stand-alone digital distance protection. IEEE Trans. Power Deliver., 9: 480-491. DOI: 10.1109/61.277720

2. Kezunovic, M., Y.Q. Xia, Y. GUo, C.W. Fromen and D.R. Servcik, 1996. An advanced method for testing of distance relay operating characteristic. IEEE Trans. Power Deliver., 12: 72-82. DOI: 10.1109/61.568227

3. Thomas, D.W.P. and M.S. Woolfson, 1997. Voltage and current phasor estimation during abnormal conditions for transmission line protection schemes. Proceeding of the 6th International Conference on Developments in Power System Protection Schemes, Mar. 25-27, IEEE Computer Society, USA., pp: 266-269.

4. Akke, M. and J.T. Thorp, 1998. Some improvements in the three-phase differential equation algorithm for fast transmission line protection. IEEE Trans. Power Deliver., 13: 66-72. DOI: 10.1109/61.660852

5. El-Arroudi, K., G. Donald, T. Mc Gillis and R. Brearley, 2004. The performance specification of transmission line protection using a knowledge-based approach. IEEE Trans. Power Deliver., 19: 1049-1056.
6. Suzuki, K., T. Iwamoto, T. Komukai and T. Hirkaw, 1980. Interactive computation system of distance relay setting for a large scale EHV power system. IEEE Trans. Power Apparatus Syst., PAS-99: 165-173.

7. Postforosh, J.M. and J. Akamine et al., 1991. Computer aided coordination of line protection schemes: IEEE committee report. IEEE Trans. Power Deliver., 6: 575-583. DOI: 10.1109/61.131114

8. Zheng, Z., K.K Li, X.G. Yin and D.S. Chen, 2000. Adaptive application of impedance estimation algorithms in distance relay. Proceedings of the 5th International Conference on Advances in Power System Control, Operation and Management, Oct. 30-Nov. 1, APSCOM, Hong Kong, pp: 269-274. http://ieeexplore.ieee.org/xpl/freeabs_all.jsp?tp=\&a rnumber $=950309 \&$ isnumber $=20549$

9. Tseng, K.H., W.S. Kao and J.R. Line, 2003. Load model effects on distance relay settings. IEEE Trans. Power Deliver., 18: 1140-1146. DOI: 10.1109/TPWRD.2003.817507

10. Coury, D.V., 1998. Artificial neural network approach to distance protection of transmission lines. IEEE Trans. Power Deliver., 13: 102-108. DOI: $10.1109 / 61.660861$

11. Kim, C.H., J.Y. Heo and K.R. Aggarwal, 2005. An enhanced 3-zone algorithm of a distance relay using transient components and state diagram. IEEE Trans. Power Deliver., 20: 39-46. DOI: 10.1109/TPWRD.2004.837827(410) 2

12. Xiaoyao Zhov, Haifeng Wang, R.K. Aggarwal and Phil Beaumont, 2006. Performance evaluation of a distance relay as applied to a transmission system with UPFC. IEEE Trans. Power Deliver., 21: 1137-1147. DOI: 10.1109/TPWRD.2005.861329

13. Arrllaga, J. and N.R. Watson, 1985. Power System Harmonics. John Wiley and Sons, Ltd.

14. Grainger, J.J. and D.W. Stevenson, 1994. Power System Analysis. International Edn., McGraw Hill, USA. 